\title{
ORGANIZATIONS, LABOR MARKETS, AND GENDER INTEGRATION IN ACADEMIC SOCIOLOGY
}

\author{
STEPHEN S. KULIS \\ KAREN MILLER-LOESSI \\ Arizona State University
}

\begin{abstract}
This paper examines several facets of gender integration within academic sociology: total segregation, as in all-male faculties; appointments of women in token or solo positions; variations in the departmental faculty sex ratio; and the "ghettoization" of women in lower academic ranks and positions with heavy committee assignments. These outcomes are analyzed at the organizational level as the product of the operation of internal and external labor markets in academia. Drawing on a representative 1984 national survey of sociology departments $(N=230)$, multivariate analyses indicate that a large proportion of the variation in gender integration from one department to the next can be predicted from the organizational context. Several organizational factors appear to militate against total segregation (all-male faculties) while promoting balance in the faculty sex ratio and in the distribution of academic rank. These include demand for labor in the form of job opportunities, especially those created through turnover; women in the institutional power structure, including a separate women's studies program; and a state legislative climate favoring women's legal and political rights.
\end{abstract}

\section{INTRODUCTION}

The role of organizations in generating and reinforcing segregation by gender has received increased research attention since the seminal work of Kanter (1977). One of the useful recent advances in this area is the application of the labor-market concept to organizations (Bielby and Baron 1984; Kalleberg and Sörensen 1979). Organizations have internal labor markets by virtue of the way in which they are internally organized, while at the same time they exist in external labor markets that direct the flow of labor into and out of the organization. Aspects of these labor markets may have a major impact on the extent of integration by gender within an organization.

This paper examines the labor-market determinants of different configurations

Direct all correspondence to: Stephen S. Kulis, Department of Sociology, Arizona State University, Tempe, AZ 85287-2101. e-mail: atssk@asuacad.bitnet 
of women's participation in one type of organizational setting: departments of sociology in American colleges and universities. We present data on numbers and proportions of women on sociology faculties ranging from no representation to an approximation of full integration in terms of equal numerical representation of both genders. We are also able to examine some evidence with respect to "ghettoization" within departments-a concept applied by Reskin and Roos (1990; Roos and Reskin 1992) to occupations. Ghettoization in departments involves women's placement in lower-rank positions and women's placement in departments' "service sector" - committee work. Our aim, in part, is to document these empirically distinct, though interrelated, dimensions of integration. Our larger aim is to help identify institutional and societal influences that promote gender integration as well as those that do not.

Because it is an instance of a "feminizing" occupation-one with a rapidly growing proportion of women (Jones and Roos 1991) - academic sociology is an illuminating case for examining issues of gender integration. During the 1980s, women became the majority among sociology graduate students (Nigg and Axelrod 1981; Kulis 1988) and earned nearly as many doctoral degrees as men (Coyle 1986), creating the potential for rapid changes in the sex ratio of sociology faculties. As gaps in the educational attainment of men and women have narrowed both quantitatively and qualitatively (Carter and Carter 1981; Vetter 1984), it is becoming less credible to view persisting gender inequities in academia principally as the result of human capital factors (England 1982). Since increasing numbers of qualified women are entering academic careers, institutional factors appear ever more salient in explaining variation in the extent to which they become fully integrated into sociology departments.

Over the last decade, investigations of women's integration, or lack of it, in the occupational sphere have focused increasingly on the structure of labor markets and organizations rather than on individual-level gender differences in socialization, education, family responsibilities, work experience, and achievement. These new approaches explore the ways institutional structures shape individual careers, often with different implications for women than for men. Although the units of analysis-occupations, professions, economic sectors, and organizations-are not always the same, these investigations all focus on aspects of internal or external labor markets. Internal labor markets are created within organizational settings by specific administrative procedures and the nature of the division of labor. Bielby and Baron (1984), for example, report that gender segregation is more severe when measured within organizations on the basis of the distribution of job titles than when it is based on the gender composition of occupations at the macro level. Meanwhile, studies of external labor markets-structures and process that govern the supply, demand, and competition for labor-have indicated ways in which labor is directed into various occupations, jobs, and organizations (e.g., Kalleberg and Sörensen 1979). While agreeing on their importance, there is little consensus among researchers on the most salient aspects of either internal or external labor markets (Baron and Bielby 1980). 
In studies of academic labor markets, the list of potential important factors has steadily lengthened. Regarding internal labor markets, there are long-standing claims that an institution's size, prestige, and emphasis on research influence its administrative practices (Bernard 1964; Blau 1973), with potentially profound consequences for women. More recent studies have highlighted external labor market factors as well: the level of competition for faculty among colleges and universities in the local area (Szafran,1984); the "density" of opportunities for faculty appointments in a city or region (Marwell, Rosenfeld, and Spilerman 1979); and proximity to the graduate schools that produce most of the discipline's new scholars (McGinnis and Long 1988). Each academic institution, and perhaps each of its departments, can be seen as an internal labor market with specific formal and informal rules governing entry, promotion, and access to rewards. In addition, each is situated in a position of relative advantage or disadvantage with respect to the operations of external labor markets. Each institution also exists in a larger political context in terms of its auspices (public versus private), the state legislative "climate" (the extent to which the state is progressive on women's issues and thus a nurturing environment for gender integration in its universities), and the institution's degree of dependence on federal funding (the extent to which the institution is bound by federal affirmative action policy mandates). All of these factors-internal and external-may constrain or facilitate employment opportunities in each institution in ways that differ for men and women.

In a previous paper (Kulis and Miller-Loessi 1992), we examine how a subset of these factors affected change over time in women's representation in sociology departments in the western United States. In this analysis, we broaden the range of variables included and look at a sample of institutions in all fifty states in a cross-sectional analysis.

\section{Demand for Labor}

Rapid change in the sex composition of male-dominated occupations, professions, and disciplines requires either a dramatic increase in job opportunities or high rates of job turnover. In academic departments, the prevalence of tenure depresses job mobility at advanced ranks, and new appointments typically are occasioned by retirements or the expansion of the faculty. The level of demand for labor is a crucial enabling condition for altering women's faculty representation and status, and one that varies widely from department to department. In itself, however, demand for labor does not guarantee increased opportunities for women. Numerous new faculty appointments are necessary, but not sufficient, conditions for rapid changes in gender inequities. Depending on political considerations, increases in demand may simply increase jobs for men. Here it may be important to distinguish opportunities created through expansion rather than simple turnover. Political resistance to gender integration might be defused through faculty expansion because the opportunity structure can be configured both to preserve the absolute and the proportional dominance of men. Gender 
integration through faculty turnover alone is a more serious and direct threat to existing power distributions. These arguments assume, however, that supplies of qualified female candidates are adequate, and fairly uniformly distributed with respect to job opportunities. This depends on external labor-market factors we address below.

\section{Organizational Scale}

In part because it is related to the magnitude of demand for labor, organizational size may also influence the pace and direction of gender integration. Size is an important feature of internal labor markets because it is closely associated with an array of organizational characteristics that have been identified as salient to the recruitment, promotion, and salaries of women, especially in academia. Larger colleges and universities tend to be more heavily research-oriented and prestigious (Blau 1973), conditions that have been viewed as impediments to the participation of women (Bernard 1964; Graham 1978; although see Kulis and Miller-Loessi 1992, for a regional variation on this pattern $\left.{ }^{1}\right)$. Larger scale may also increase the availability of discretionary financial resources (Kimberly 1976) that can be used either to reduce or intensify gender inequities. Finally, size is associated with an important structural property: the degree of formalization in recruitment and promotion procedures (Child 1973; Pfeffer 1977), which may promote fuller gender integration. These conflicting implications of the correlates of organizational size make it difficult to predict precisely its impact on women's integration. Organizational size has been examined repeatedly in studies outside of the academy, but the results have been divided among those finding a positive relationship between size and gender equity (Lyle and Ross 1973; Schwartz 1971), virtually no relationship (Shepherd and Levin 1973), a curvilinear effect (Bielby and Baron 1984), and an inverse relationship (Baron and Bielby 1982; Shepherd 1969).

Research on the effect of formalization, however, is quite consistent: firms with written personnel rules and procedures tend to recruit and promote more women (Mayhew 1968; Abramson 1975). In studies of academia, one possible approach to this problem is to examine size while controlling for its most salient correlates: prestige, research orientation, demand for labor, and financial resources. With these factors held constant, we expect that size-measured at both the departmental and institutional level ${ }^{2}-$ will indicate the degree of formalization in personnel decisions.

\section{Organizational Resources: Research, Prestige and Finances}

Research orientation is another feature of internal labor markets in academia with close links to women's career prospects. The degree of emphasis on research productivity at the department and college level influences goals and policies vis-à-vis hiring, promotion, and the allocation of tenure and salary. Although the reasons for it are vigorously debated (Cole 1979; Knorr-Centina 
1981; Reskin 1980), women continue to be dramatically underrepresented in research-oriented institutions (Simeone 1987). There is more general agreement about the existence of sex differences in research productivity. Women scientists publish less than men (Fox 1983), take longer to reach their productivity peaks (Thibault 1987), are less persistent in the face of rejection by editors (Max 1982), receive outside funding for research less often (Rong, Grant, and Ward 1988), and their scholarly work is less widely disseminated (Ferber 1988). Although recent studies detect a significant narrowing in this productivity gap, particularly among new cohorts of faculty (Cole and Zuckerman 1987; Mackie 1985; White 1985), the legacy of the past leaves women more often than men in roles that emphasize teaching rather than research. Gender gaps in promotion, tenure, and salary have been linked to women's disproportionate location in teachingoriented institutions (Aisenberg and Harrington 1988; Astin and Bayer 1979; Fox 1983), where heavier teaching and administrative loads, less graduate assistance, fewer productive colleagues, and a paucity of library and computer resources pose major barriers to research productivity. In addition, women may be excluded from the "invisible colleges" (Crane 1972) of informal networks of scholars that sponsor or promote research careers and give access to "insider" information that leads to academic success (Bernard 1975). These arguments suggest that departments with strong research contexts will be less hospitable and/or attractive to women sociologists, thus impeding gender integration.

Women's status has been linked to the prestige of the institution, another important feature of the internal labor market. Faculty members appear to accord differential prestige to institutions largely on the basis of their research reputations (Jones, Lindzey, and Coggeshall 1982). Another measure of prestige is the quality or selectivity of the undergraduate program, which has been shown to vary inversely with women's share of faculty positions (Tolbert 1986; Bach and Perrucci 1984). One explanation for this pattern is that prestige is a powerful resource that can be used as an incentive to attract recognized scholars and researchers (Blau 1973). Women academics typically have been located outside of informal prestige networks (Caplow and McGee 1958), perhaps making them less attractive than male candidates because they are seen as less effective in recruiting others or in augmenting departmental prestige. Although it may be changing (Smelser and Content 1980), female faculty remain less well represented in the more prestigious institutions than elsewhere in the academy (National Research Council 1979; see note 1). Still, there is some evidence that women's disadvantages in obtaining appointments in prestigious institutions do not necessarily hamper their progress in securing central academic rewards. Although there are proportionally fewer of them than in less prestigious departments, women sociologists in top-ranked departments occupy more advanced ranks with tenure than their national peers, and gender gaps in rank and tenure are also narrower in top-ranked departments (Kulis 1988). While barriers to entry may be high, the relatively few women who gain admittance may find that academic rewards are allocated more fairly thereafter in prestigious institutions.

Financial resources have also been cited as important factors in the treatment 
of women within universities (DiNitto, Martin, and Harrison 1982). Szafran (1984) and Tolbert (1986) reported inverse relationships between women's proportional representation on the faculty and revenues per student. Thus, it appears that women are better represented at less financially robust schools, which, to a substantial degree, is a reflection of their lower prestige. Controlling for prestige, however, it is not immediately clear how the institution's financial position might influence women's status. Some organizational theorists have argued that surplus financial resources beyond those minimally necessary for operation provide top executives with the organizational "slack" (Cyert and March 1963) to act on personal preferences even when they lead to administrative inefficiencies (Child 1972). "Slack" resources provide the institution with a competitive edge in recruiting and retaining the most desired faculty, but this advantage could be used to pursue sought-after scholars regardless of gender. Financial robustness may be seen, then, as an enabling condition whose impact is conditioned by political factors that determine whether administrative goals are focused on redressing gender inequities.

\section{Segmented Labor Markets}

The degree of segmentation in the internal labor market is a third feature of these markets with quite direct implications for women's status. Segmentation appears most strikingly in the creation of "irregular" faculty positions such as lecturers and instructors. These appointments have one or more features (parttime, non-tenure-track, low-pay) that lower their status relative to regular faculty (Szafran 1982). More insidious forms of segmentation may occur as "irregular" faculty are allocated to roles within the department emphasizing service and undergraduate teaching rather than graduate training and research. In each of these manifestations, a segmented internal labor market creates lower-status positions where women may find that employment opportunities are more plentiful and easier to secure. Segmentation may then simultaneously improve women's numerical representation in the department while lowering their status relative to men.

\section{Institutional Power Distributions}

Allocations of power and authority within the institution are another component of the internal labor market with implications for women's status on the faculty. The existence of a women's studies program may indicate clout within the power structure of the institution, although this may depend on the exact administrative nature of the program (Bach and Perrucci 1984). Females within the formal decision-making structure can influence personnel decisions directly by establishing criteria for recruitment and promotion, and by monitoring their implementation at lower levels (Caplow and McGee 1958; Kenen and Kenen 1978). ${ }^{3}$ Highly placed women administrators-presidents, deans, and depart- 
ment chairs-may be more sensitive to, and more vigilant in detecting discriminatory criteria, and can help to transform organizational culture such that gender bias is reduced among all decision-makers. Szafran (1984) found that institutions with female deans appointed more female faculty members university-wide, but the precise role of female administrators is often difficult to isolate. First, although their numbers are increasing, female college presidents tend to be appointed to head less prestigious, and/or financially troubled institutions (Leatherman 1991), factors that are also implicated in women's faculty representation. With cross-sectional data it is impossible to determine the extent to which improvements in women's faculty status and representation tend to precede or to result from the appointment of female administrators and department chairs.

The distribution of power, authority, and decision-making is also influenced by the existence of collective bargaining agreements, which may increase the degree of formalization and the openness of personnel procedures. But collective bargaining agents exist typically to protect and enlarge the privileges of long-term employees, not those who may be challenging those privileges. This has led some to suggest that unions will not promote the interests of women and minorities unless those groups are prominent in the union membership (Szafran 1982), and that this is unlikely to occur, given their historical pattern of exclusion from the academic workplace.

\section{Government Influence and Dependence}

Outside political influences can also intervene in an institution's decisionmaking. Among the many external publics that may be important, governmental bodies are likely to be potent and recognizable influences. Institutions heavily dependent on federal funds may be particularly vigilant establishing nondiscriminatory personnel records, and especially likely to develop procedures to prevent sex discrimination in hiring and promotion (Pfeffer and Salancik 1978; Salancik 1979). Access to personnel data and accountability would presumably be greater in public than in private institutions. Clearly, the effect of public accountability on gender equity would depend on how aggressively affirmative action and equal employment opportunity are enforced by the government (Perrucci 1986). One way of measuring possible variations in this political "climate" is to examine the pattern of state legislation directed at securing women's legal, political, and economic rights and protections.

\section{Ecological Effects}

While women have rapidly approached parity with men in earning doctoral degrees in disciplines like sociology (National Science Foundation 1990), it has been suggested that the supply of female labor is more geographically constrained. This is an important feature of the external labor market of academic 
institutions. Women may be less likely than men to have the mobility needed to compete in national markets because they are disproportionately likely to be married to fellow academics. Abramson (1975) and Marwell et al. (1979) suggest that an absence of alternative employers in the immediate vicinity impairs the ability of married women to maximize the financial and status returns on their qualifications. The fact that large metropolitan areas offer more alternative employment options to women (Rosenfeld 1984) may give them bargaining power to achieve gender equity in departments located in urban settings. Of course, the greater supply of academic women in many such areas may offset this effect.

The supply of labor may also be more regionally constrained for women than for men. To the extent that their husband's careers have taken precedence in deciding when, where, and whether to move, women doctoral candidates may, over time, become more firmly rooted in the locations in which they receive their training. In sociology, as in other disciplines, a large plurality of doctoral degrees are produced by departments clustered in a few areas of the country: the Northeast, California, and sections of the Midwest. The potentially denser presence of female sociologists in these areas may increase the odds that women will be represented among the faculty of departments located there, but the greater supply of female labor may be a competitive disadvantage in securing other academic rewards.

\section{DATA AND MEASUREMENT}

\section{The National Sample of Departments}

The main body of data for this study come from a 1984 survey of sociology departments in the United States (Kulis et al. 1986). We used the American Sociological Association's Directory of Sociology Departments to identify four-year colleges or universities that had either a sociology department or a "social science" department offering the bachelor's degree in sociology. The sampling frame included all such departments from the western United States, ${ }^{4}$ and a random sample of the remaining departments across the nation, stratified by size of the student body and whether graduate sociology degrees were offered.

Questionnaires were mailed to the chairs of eligible departments, requesting that they enumerate the sociologists within the department-including adjunct and part-time faculty-along with their sex, race or ethnicity, academic rank, tenure status, and committee assignments. They also detailed the sex and eth$\mathrm{nic} / \mathrm{racial}$ composition of the faculty members who had begun or who had ended appointments in the department within the previous five years. A response rate of 91 percent $(N=230)$ was obtained, making the weighted sample highly representative of the nation's sociology departments in 1984. We also drew upon secondary and published sources to compile an array of salient organizational and environmental characteristics of these departments and their academic institutions. 


\section{Measures of Gender Integration}

We chose to examine several dependent variables in this study, each representing a different facet of gender integration. Each variable is measured as an aggregate characteristic at the departmental level. Two of these address different dimensions of women's faculty representation in 1984: the absolute number of women within the department's faculty, and women's proportional representation, i.e., the percentage of faculty positions held by women. A third measure gauges disparities in the distribution of men and women across four academic ranks: full professor, associate professor, assistant professor, and instructor/lecturer. Faculty at ranks other than these (e.g., unspecified "adjunct," visiting, and emeriti professors) were excluded from this portion of the analysis because of small numbers and lack of comparability across departments.

We employ an index of segregation, $\mathbf{H}$ (Theil and Finizza 1971), defined as

$$
\underset{p}{H}=\frac{E-\sum_{i=1}^{N} \frac{T_{i}}{T} E_{i}}{E}, \text { where } E_{i}=p_{i} \log _{2} \frac{1}{p_{i}}+\left(1-p_{i}\right) \log _{2} \frac{1}{1-p_{i}}, E=p \log _{2} \frac{1}{p}+(1-p) \log _{2} \frac{1}{1-p^{\prime}}
$$

$N$ is the number of academic ranks in the department, $T_{i}$ is the number of faculty at the $i^{\text {th }}$ rank, $T$ is the total number of faculty within the department, $p_{i}$ is the proportion female at the $i^{\text {th }}$ rank, and $p$ is the proportion female within the departmental faculty as a whole. This index differs from most other measures of segregation, such as the index of dissimilarity $\mathbf{D}$ (Duncan and Duncan 1955), 5 in that it treats gender skewness at a given academic rank as a more serious indicator of segregation if the sex ratio in the department overall is balanced rather than highly skewed. This measure varies between 0 and 1 , expressing sex-based segregation in academic rank relative to the degree of integration that is theoretically possible given the faculty sex ratio. $\mathbf{H}$ addresses the concern that skewed distributions in academic rank are especially glaring or remarkable when the supply of women faculty for advanced ranks is relatively ample. Higher values for this index indicate more severe sex segregation by academic rank.

Last, we investigate sex differences in academic service activities by contrasting the mean number of departmental or college/university committee assignments of female and male faculty in the sociology department. Average committee loads for women in excess of those for men are a possible indication of labormarket segmentation among the faculty, with women doing more of the institution's "housework." Allocating female faculty more burdensome service activities may detract from their research efforts, and their success in tenure, promotion, and salary decisions.

\section{Operationalization of Internal and External Labor Market Factors}

There are seventeen independent variables in the analyses that follow. Each represents some facet of the internal or external labor market of the sociology 
department or its institutional environment. Two are indicators of the sociology department's demand for labor and the magnitude of opportunities for new faculty appointments. Faculty expansion or contraction is measured as the rate of real growth in the number of full-time and part-time faculty members from 1975 to 1984 , i.e., the change in faculty size as a percentage of initial size. Faculty turnover is defined as the percentage of initial faculty positions that were vacated and refilled, apart from growth or contraction in the faculty.

Initially, we attempted to "tease out" the separate effects of institutional size, prestige, and research orientation by including several indicators of each in multivariate analyses. When these variables proved to be too highly interrelated to produce meaningful results, we turned to confirmatory factor analysis. This verified the existence of three interrelated constructs centering on size, research, and prestige. The strongest factor to emerge from this analysis was organizational size, with factor loadings above .67 on several indicators: student enrollment and faculty size, both within the sociology department and institution-wide. This factor may be interpreted as a structural measure of institutional scale and/or as a proxy for formalization of recruitment and promotion procedures. The same analysis produced a second factor score relating to research activity and resources within the institution. This factor loads above .44 on the following components: extramural research funds as a percentage of the institution's expenditures; the institution's Carnegie Foundation (1987) research classification; the number of library volumes in the institution; the highest degree offered within the sociology program; and the number of sociology graduate students. ${ }^{6}$ Collectively, we interpret these variables as indirect measures of the commitment and availability of resources for research at the departmental and university level.

The factor analysis also produced a multiple-indicator construct relating to the quality and selectivity of the institution's undergraduate degree program, which we treat as a measure of institutional prestige. This factor has loadings above .58 on the ratio of undergraduate admissions to applications, the percentage of all faculty who hold doctoral degrees, and average SAT/ACT scores for freshmen students. ${ }^{7}$ Another variable in our results is a single indicator of robustness or "slack" in financial resources, measured as total college/university expenditures per student in 1984. This last variable, and the size, research, and prestige factor scores are all positively interrelated, yet still distinct.

Segmentation of the department's internal labor market into a primary and secondary sector is measured by the percentage of all 1984 faculty positions in sociology that were held at the instructor or lecturer level.

Aspects of the institution's power structure are also measured: the presence or absence of (1) women's studies programs and (2) collective bargaining agreements; and females in executive positions as (3) president and/or liberal arts dean, and as (4) chair of the sociology department.

Finally, we examine six features of the external labor market of these sociology departments. Three are ecological measures: region of the country, size of the 
locale, and the number of other colleges and universities in the area. After investigating the first two with more elaborate breakdowns, we found that the key effects could be captured with simple dichotomies between locations in the Northeast versus all other regions, and between large metropolitan areas with populations of at least 500,000 versus smaller settings. As a measure of the number of competing or alternative academic employers in the area, we sorted the zip codes of 1,793 four-year colleges and universities into Metropolitan Statistical Areas, tallied the results, and matched the sums to the institutions in our sample. ${ }^{8}$

As summary measures of the political "climate" for women at the state level, we drew upon indicators developed in a study of the incidence of 88 public policies relating to equity for women (Blair and Savage 1984). One variable we used involves state policies that extend legal and political protections to women: "prohibition of sex discrimination in employment and education, fair housing, and home finance," and policies related to suffrage and commissions monitoring the status of women (Blair and Savage 1984:59). A second variable focused on policies that provide economic rights to women in the workplace and in obtaining credit. These variables are factor scores reflecting the simple presence of these state policies. ${ }^{9}$

The last of our variables measures institutional dependence on federal and state governments: the percentage of total college/university revenues derived from those sources.

\section{RESULTS}

\section{Predictors of Women's Faculty Presence}

In 1984, three out of every ten of the sociology departments in our sample had no female faculty members. What distinguished this all-male minority from other departments where women held at least one faculty position? The results of a logistic regression analysis of women's presence (versus complete absence) on the sociology faculty appear in Table 1 . The most powerful predictor of a gender-integrated department is organizational size. Measured in standardized units, each one-unit increment in size increases the odds that a female sociology faculty member will be present by over 37 to 1 . The importance of size can be grasped more immediately by contrasting the smallest and largest departments. Of the smallest departments-those with five or fewer faculty-over one-half had no women. But of the larger departments-those with 15 or more facultyevery one had at least one female sociologist.

Other aspects of the institution's internal economy increase the odds that women will be on the faculty, though far more modestly than the effect of size. Recent opportunities to make faculty appointments, through both faculty growth and turnover, favor women's presence somewhat. In addition, it appears that more highly segmented internal labor markets make more room for 
TABLE 1

Logistic Regression of Women's Presence in Department

\begin{tabular}{lcrr}
\hline Institutional Predictors & $B$ & $S . E$. & Exp(B) \\
\hline Sociology Faculty Growth & $.125^{*}$ & .061 & 1.133 \\
Sociology Faculty Turnover & $.016^{*}$ & .007 & 1.016 \\
Organizational and Departmental Size & $3.625^{* * *}$ & .939 & 37.534 \\
Research Orientation & 1.653 & 1.264 & 5.225 \\
Prestige/Selectivity & -.003 & .306 & .997 \\
Expenditures per Student & .478 & .614 & 1.613 \\
\% Sociology Faculty at Instructor/Lecturer Rank & $.076^{* *}$ & .029 & 1.079 \\
Women's Studies Program $(Y=1, N=0)$ & $1.073^{*}$ & .511 & 2.925 \\
Collective Bargaining Agreement $(Y=1, N=0)$ & -.544 & .973 & .580 \\
Female President or Liberal Arts Dean $(Y=1, N=0)$ & $2.366^{* *}$ & .858 & 10.658 \\
Large (500,000) Metropolitan Area $(Y=1, N=0)$ & -.822 & .769 & .440 \\
Located in Northeast ( $Y=1, N=0)$ & $1.549^{*}$ & .646 & 4.704 \\
Number of Four-year Colleges/Universities in MSA & .028 & .022 & 1.028 \\
State Legislation for Women's Legal/Political Rights & $.824^{*}$ & .345 & 2.279 \\
State Legislation for Women's Economic Rights & -.007 & .304 & .993 \\
Percent of Revenues from Federal/State Government & -.012 & .012 & .989 \\
Constant & -2.252 & & \\
Gamma (Somer's d) & .782 & $(.772)$ & \\
\hline
\end{tabular}

${ }^{* * *} p<.001 ; \quad * * p<.01 \quad * p<.05$

women, as indicated by the effect of having a higher proportion of positions at the instructor or lecturer level.

Women in leadership positions also appear to make a difference. Female sociologists are over ten times more likely to be found in institutions with a female president or liberal arts dean than in institutions with males in both of those leadership positions. Female sociologists are also almost three times more likely to be found in institutions with women's studies programs. We cannot determine the exact role of women's studies programs or female presidents and deans in generating faculty opportunities for female sociologists. We do not know how many women hold joint appointments in sociology and women's studies, and we can only speculate about the specific role of female administrators in the hiring of female sociologists. Women's presence in higher administration may result from unspecified factors that create a more favorable institutional climate for academic women.

The constraints of external labor markets play a role that may be even more complex. Departments located in the Northeast are almost five times more likely to have female sociology faculty than those located in other regions, and departments in states that have enacted legislation aimed at securing women's political and legal rights tend to have women sociologists more often than those in other states. We will have more to say about these factors after examining other aspects of women's integration. 

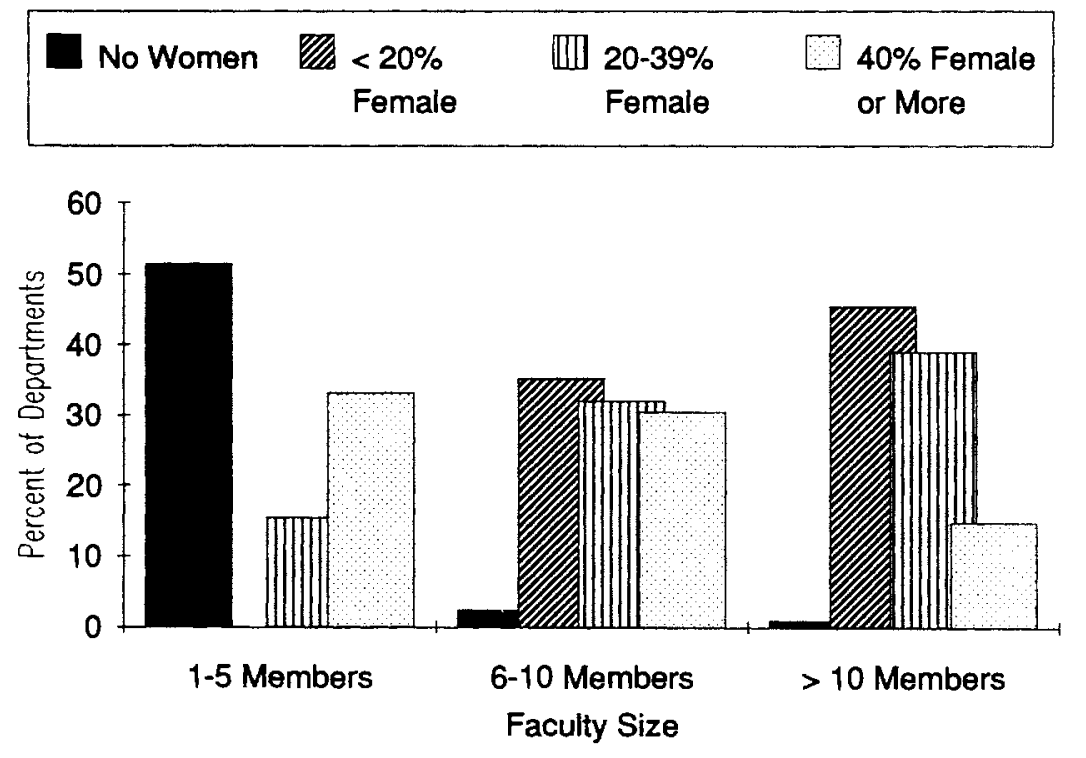

Figure 1

Proportional Representation of Female Faculty by Faculty Size

\section{Solos and Tokenism}

The sheer presence of female faculty is a crude gauge of integration, disguising considerable variation in the level of representation for women. Here it is useful to distinguish between numbers and proportions, each of which has somewhat different implications for women's representation in a department. Absolute numbers are important for the job opportunities they represent, for opportunities to establish networks among women, and for offering numerous and diverse female role models for students. Proportions, on the other hand, are especially important with respect to the balance of power and decision making in the department (see Kanter 1977 for a discussion of the importance of the sex ratio per se for power structures in the corporate context).

Although there is a tendency for women's proportional representation to increase as their absolute numbers grow $(r=.44)$, the relationship between these two ways of gauging women's faculty representation is strongly mediated by departmental size: with increasing faculty size, women's absolute numbers tend to increase, but their proportional representation tends to decline (Figure 1). Among departments with more than ten faculty members, over one-half (55 percent) have at least four female faculty members, but women commonly comprise less than one-fifth of the faculty in these departments (46 percent). Women's proportional representation varies most widely in the very smallest depart- 
TABLE 2

Logistic Regression of Absolute Indicator of Tokenism

\begin{tabular}{lccr}
\hline & \multicolumn{3}{c}{$\begin{array}{c}\text { Solo female in department (1) versus } \\
\text { two or more (0) }\end{array}$} \\
\cline { 2 - 4 } lnstitutional Predictors & \multicolumn{1}{c}{. } & \multicolumn{1}{c}{ S.E. } & Exp(B) \\
\hline Sociology Faculty Growth & $.084^{*}$ & .034 & 1.087 \\
Sociology Faculty Turnover & .005 & .007 & 1.005 \\
Organizational and Departmental Size & $-1.584^{*}$ & .700 & .205 \\
Research Orientation & $-2.614^{*}$ & 1.220 & .073 \\
Prestige/Selectivity & $-1.332^{* *}$ & .410 & .264 \\
Expenditures per Student & $1.862^{*}$ & .802 & 6.437 \\
\% Sociology Faculty at Instructor/Lecturer Rank & $-.064^{*}$ & .032 & .938 \\
Women's Studies Program $(Y=1, N=0)$ & -.036 & .606 & .965 \\
Collective Bargaining Agreement $(Y=1, N=0)$ & -.883 & .954 & .414 \\
Female Sociology Chair $(Y=1, N=0)$ & $-1.888^{*}$ & .849 & .151 \\
Female President or Liberal Arts Dean $(Y=1$, & -.372 & .739 & .690 \\
$N=0)$ & & & \\
Large $(500,000)$ Metropolitan Area $(Y=1, N=0)$ & $-1.827 \dagger$ & .978 & .161 \\
Located in Northeast $(Y=1, N=0)$ & -1.053 & .664 & .349 \\
Number of Four-year Colleges/Universities in MSA & $-.057^{*}$ & .026 & .944 \\
State Legislation for Women's Legal/Political Rights & $1.149^{*}$ & .530 & 3.155 \\
State Legislation for Women's Economic Rights & .546 & .461 & 1.727 \\
Percent of Revenue from Federal/State Government & -.003 & .018 & .997 \\
Constant & -11.232 & & \\
Pseudo $r 2$ : Gamma (Somer's d) & .651 & $(.646)$ & \\
\hline
\end{tabular}

*** $p<.001 ; \quad * * p<.01 \quad * p<.05 \quad t p<.10$

ments. About one-half of these have no female sociologists at all, yet a third of the departments are at least 40 percent female.

To further isolate the characteristics of departments where women were least, and best, represented, we conducted a separate analysis that was restricted to departments with at least one female sociologist. Table 2 presents the results of a logistic regression analysis isolating characteristics of departments where women tend to be "solos," and possibly face problems of isolation and heightened visibility, versus departments having at least two women.

As would be expected, size plays an important role in tokenism: the odds of having a single female sociologist are lower in the largest departments. Similarly, more research-oriented and more prestigious departments tend to avoid hiring solo women. Ironically, recent faculty growth is implicated in creating positions for solo women.

More intriguing is the sizable effect of financial resources (expenditures per student) on the chances of having only one instead of more than one woman. It raises the question: does concern about faculty gender integration diminish in the more financially robust institutions after they have used their financial ad- 
vantages to recruit a single female sociologist, perhaps a relatively prominent one?

Other effects are more easily explained. Women have better odds of avoiding solo status when lecturers and instructors are relatively numerous, or the department chair is female. This suggests in the first instance that some progress toward numerical representation for women occurs at the cost of assignment to positions with inferior status and rewards. In the second instance, we should again caution that the relationship between the role of departmental chairwomen and female representation on the faculty is likely to be reciprocal.

Geography plays an important role as well. The odds that women will be in positions as tokens are lessened when the department is located in a large metropolis, and within a dense cluster of four-year colleges and universities. There are also rather sizable effects of state political climate, but in an unexpected direction. States that extend legal and political protections to women tend more often to appoint solo women. This may indicate a phenomenon of minimal compliance among institutions that in other states would have no women at all and thus would not appear in this particular analysis; in fact, departments with only one woman are located in more politically progressive states than departments with no women (data not shown).

The statistics at the bottom of Table 2 indicate that these predictors can correctly place large pluralities of the departments into the correct category of tokenism.

\section{Sex Segregation in Academic Rank and Committee Loads}

Next, we examine organizational predictors of sex differences in academic rank and committee loads among the department's sociology faculty, both measures of the extent to which women are "ghettoized" in inferior positions, and relegated to less valued work (Table 3 ). The segregation index increases in magnitude to the extent that men and women in the department occupy different ends of the academic rank ladder, and is accentuated further as the overall sex ratio approaches parity. The measure of committee-load differentials takes on positive values to the extent that women in the department have more numerous committee assignments than their male counterparts, and take on negative values when men shoulder more committee assignments than women. Because both measures produce non-meaningful values in all-male or all-female departments, 10 the analysis is restricted to gender-integrated departments, i.e., those with both some male and some female faculty.

As with total segregation and tokenism, for these two aspects of ghettoization - rank inequity and committee overload-both internal and external labor-market factors are potent predictors. In many instances, the results are not the same for the rank-segregation and committee-load measures, so we will discuss them separately, examining rank inequity first. Gender disparities in 


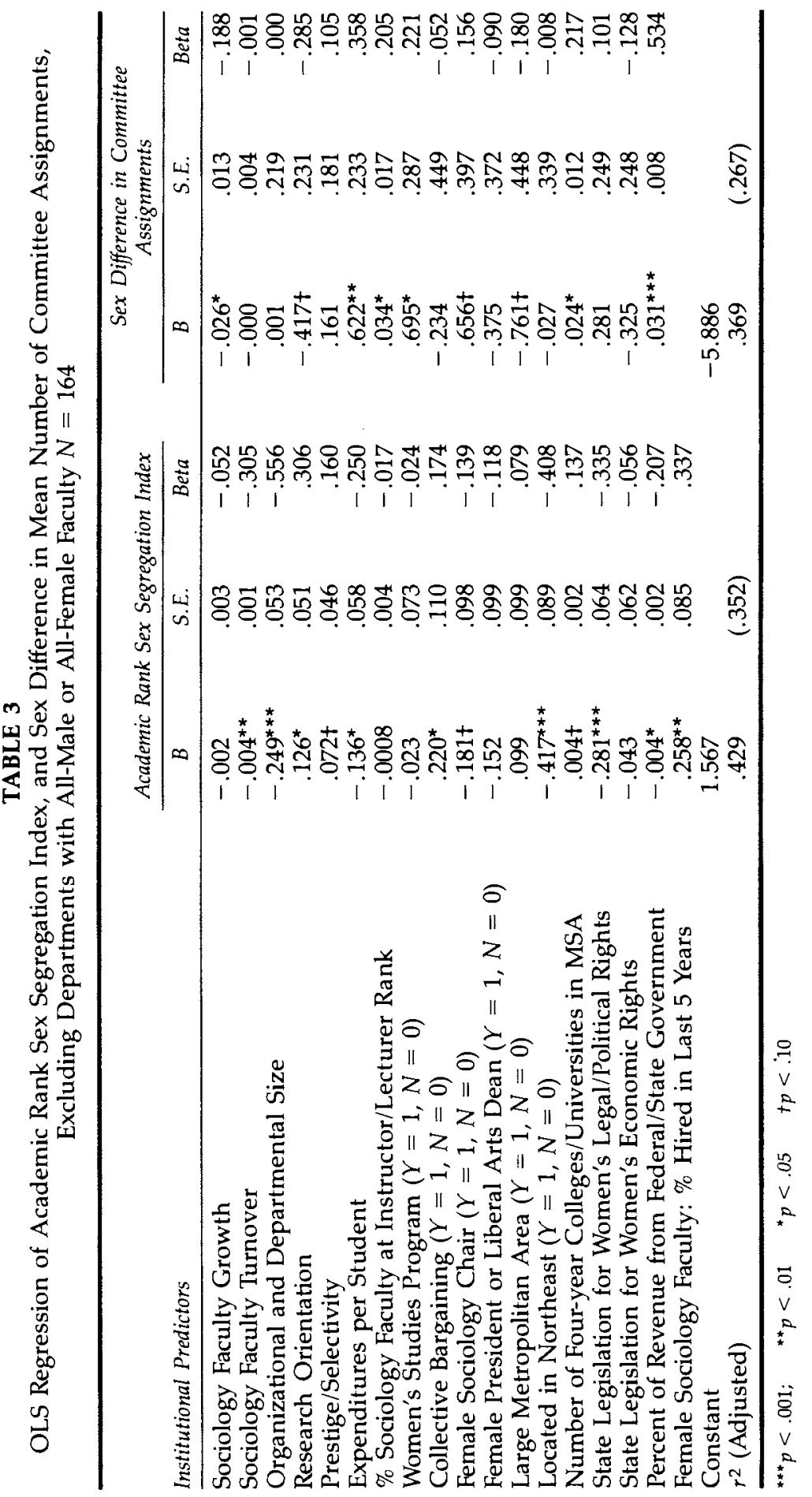


academic rank are less pronounced in the largest and most financially robust institutions, and in departments with high rates of faculty turnover. By contrast, heavily research-oriented institutions, and those with unions, tend to have sociology faculties that are more severely segregated by academic rank. Two other factors emerge at the .10 level of significance: institutional prestige is associated with greater disparity in rank, while a female department chair is associated with less sex segregation.

Of the external labor-market factors, region is the strongest predictor, with departments in the Northeast displaying considerably less disparity in academic rank than is found in other regions. In addition, institutions in states that have enacted legislation promoting women's political and economic rights have smaller gaps in rank between male and female faculty. Academic rank disparities are also inversely related to the institution's degree of financial dependence on governmental sources of revenue. One other noteworthy predictor is statistically significant at the .10 level: sex segregation in academic rank is more pronounced in local areas with the densest clusters of colleges/universities.

One of the limitations of this study is the inability to control at the individual level for sex differences in scholarly credentials, experience, and career interruptions. Some might argue plausibly that women's relatively more recent entrance into the sociological profession might place proportionally more women than men on the bottom rungs of the academic rank ladder. Intensive efforts to appoint more women in tenure-track appointments might actually exacerbate sex disparities in academic rank, at least in the short run, until women progressed to tenure and promotion decisions. We could control indirectly for this latter possibility. The last predictor in Table 3 is the percentage of female faculty whose appointments in the department came about within the previous five years. As would be expected, rank disparities intensify when the female faculty is more heavily comprised of relative newcomers. But the institutional effects continue to predict the degree of rank disparities, even when this variable is taken into account.

Paradoxically, the best predictors of the "gender gap" in committee loads have opposite effects on the degree of academic rank segregation. Committee loads for women tend to be more burdensome in institutions that rely heavily on government funding (closely related to public versus private auspices), and those with robust finances, while their load is less burdensome in researchoriented departments. For what may be quite different reasons, public institutions and financially flush institutions allocate academic rank in a more gender neutral fashion, but then assign women a heavier committee load. Women in research institutions occupy lower rungs of the academic rank ladder, but tend to be spared from a disproportionate share of committee assignments. Other factors making the "gender gap" in committee loads more burdensome for women than for men include a large share of faculty positions at the instructor/lecturer level, a location within dense clusters of colleges/universities but in smaller metropolitan areas, lack of faculty growth, and a female department chair. ${ }^{11}$ 
TABLE 4

Logistic Regression of Faculty Gender Integration (Academic Rank Segregation Under $50 \%$ and Faculty $30 \%$ Female or More)

\begin{tabular}{lccr}
\hline Institutional Predictors & $B$ & $S . E$. & Exp(B) \\
\hline Sociology Faculty Growth & .0004 & .029 & 1.000 \\
Sociology Faculty Turnover & $.019^{* *}$ & .006 & 1.019 \\
Organizational and Departmental Size & $-.781^{*}$ & .390 & .458 \\
Research Orientation & .094 & .373 & 1.098 \\
Prestige/Selectivity & -.019 & .006 & .981 \\
Expenditures per Student & $.811^{*}$ & .360 & 2.251 \\
\% Sociology Faculty at Instructor/Lecturer Rank & $.132^{* * *}$ & .027 & 1.141 \\
Women's Studies Program $(Y=1, N=0)$ & $1.319^{* *}$ & .430 & 3.741 \\
Collective Bargaining Agreement $(Y=1, N=0)$ & $-2.411^{* *}$ & .791 & .090 \\
Female President or Liberal Arts Dean $(Y=1, N=0)$ & $1.359^{*}$ & .572 & 3.893 \\
Large (500,000) Metropolitan Area $(Y=1, N=0)$ & $1.205^{*}$ & .569 & 3.337 \\
Located in Northeast ( $Y=1, N=0)$ & .315 & .502 & 1.371 \\
Number of Four-year Colleges/Universities in MSA & $.053^{* * *}$ & .016 & 1.054 \\
State Legislation for Women's Legal/Political Rights & $.835^{*}$ & .327 & 2.304 \\
State Legislation for Women's Economic Rights & -.504 & .283 & .604 \\
Percent of Revenues from Federal/State Government & $-.019^{*}$ & .009 & 1.019 \\
Constant & -9.106 & & \\
Pseudo $r 2$ Gamma (Somer's d) & .625 & $(.623)$ & \\
\hline
\end{tabular}

${ }^{* * *} p<.001 ; \quad{ }^{* *} p<.01 \quad{ }^{*} p<.05$

\section{Approaching Integration}

Clearly, institutional and environmental factors are not consistent predictors of each facet of women's faculty participation we have examined. A different mix of factors appears to be associated with each criterion of gender integration, and factors that predict in the direction of greater integration for one criterion are sometimes predictors of poorer integration for other criteria. Recognizing this complexity, we developed an indicator of fuller gender integration based both on the sex ratio and academic rank segregation. Table 4 presents a logistic regression analysis identifying departments where women make up more than 30 percent of the faculty and where the academic rank segregation index stands below 50 percent, i.e., where fewer than half of the female faculty would have to be reassigned in order to eliminate rank disparities between men and women in the department. It is important to emphasize that, jointly, these criteria are very minimal indicators of more equitable participation for faculty women, yet they are characteristic of only 37 percent of the departments in the sample. Nevertheless, these thresholds point to the institutional environments where women begin to approach men in both proportional representation and in access to positions carrying the greatest security and stature.

The analysis includes all departments in the sample, and departments without female faculty have been assigned to the poor-integration category. The results 
indicate that integration takes place more fully in small, non-unionized, financially robust institutions led by female top executives, 12 those with women's studies programs and some faculty turnover, those with a high proportion of instructors and lecturers (although this appears to be associated more closely with high proportions of women than with rank equity), those relying heavily on government revenues, those located within large metropolitan settings, those with many competing academic institutions, and those in states with a positive legislative climate for women.

\section{DISCUSSION}

This analysis has examined in detail the many ways in which the organizational contexts of sociology departments in the United States shape prospects for gender integration. Important factors include aspects of both internal and external labor markets. To summarize: organizations can impede or promote the integration of women by governing the level of demand for labor; by introducing more formalized administrative procedures; by specifying the priorities of the types of work to be done (e.g., research versus teaching) and at what level of support; by securing the presence of women in the institutional power structure; by being located in geographical and political settings that favor women's participation; and by responding to external pressure for gender equity.

In general, these factors operate as hypothesized to impede or promote integration. Let us look again at the worst case-total segregation-and the best case-relatively full (though not perfect) integration in terms of proportion and rank. Some factors idiosyncratically affect one and not the other, but there is a core list of elements that both militate against total segregation and promote fuller integration. These include: demand for labor in the form of job opportunities, especially those created through turnover; women in the institutional power structure, including the presence of a separate women's studies program; and a state legislative climate favoring women's legal and political rights.

We can draw the broad conclusion that these are aspects of the internal and external labor markets of sociology departments that are important determinants of integration for women. But our analysis demonstrates that it is also important to look at different aspects of integration separately in order to get a complete picture of how organizational context operates. Movements toward greater gender integration in these different arenas may not occur uniformly or consistently. Indeed, some of our results could be interpreted as indicating that greater integration in one arena may entail costs in another. For example, women's studies programs and female top administrators are associated with better numerical representation for women and less gender disparity in academic rank, yet are also associated with inequitably high committee loads for women; researchoriented institutions have more rank disparity but narrower gender gaps in committee loads; more financially robust institutions have less severe disparities in rank, but are more likely to place women in solo roles; large institutions are 
less likely than smaller ones to have severe disparities in academic rank, but are also less likely to approach balanced sex ratios. Even the ecological factors are not entirely consistent. The results largely support the expectation that metropolitan areas and locales with many colleges and universities attract female academics in dual-career couples. The presumably greater supply of female sociologists in these settings may be influential in reducing tokenism and promoting better proportional representation for women, but does not appear to reduce rank inequities. Though internal and external aspects of organizational context are evidently very important for women's integration, they operate in complex ways that deserve further scrutiny.

Acknowledgments: Financial support for this study was provided by the American Sociological Association, the Pacific Sociological Association, the University of Oregon Center for the Study of Women in Society, the Arizona State University Faculty Grant-in-Aid program, and the National Science Foundation (SES 8922477). Comments on the manuscript from Dula Espinosa were much appreciated.

\section{NOTES}

1. In our longitudinal study of sociology departments in the western United States, we found unexpected movements toward greater equity for women within prestigious and research-oriented institutions in the early 1980s (Kulis and Miller-Loessi 1992). These institutions had both largerthan-expected numbers of female sociologists, and less gender disparity in academic rank. Prestigious institutions also had substantially more balanced sex ratios among the sociology faculty. Moreover, all of these outcomes reflected a more rapid rate of change toward equitable participation for women than was found in other types of institutions. We could only speculate on the reasons for these findings. They might signify: a growing recognition by prestigious, research-oriented institu- tions that they must recruit the best scholars from a pool that is increasingly comprised of women; the competitive advantage that their formidable resources affords in competing for promising scholars; or perhaps a temporary increase in attention to gender issues in order to redress an embarrassing historical record in incorporating female faculty. Although we had no reason to doubt that these effects could be generalized to other parts of the country, we now have evidence that they are a regional phenomenon.

2. Perrucci's (1986) study of gender equity in sociology departments examined several organizational variables that are pertinent to our analysis. Several of these (size, percentage of women on faculty, women administrators) were found to have no effect on gender equity, or to operate in the opposite direction to that which we hypothesize. However, her study measured only institutional-level effects on departmental outcomes, and thus the units of analysis for the independent variables are not generally comparable to those we examine.

3. A more indirect factor is the "femaleness of demand," represented by the proportion of female undergraduate students. Carter (1981) cites this as a potentially important factor in the informal influence network that generally promotes greater female faculty representation. We do not examine this factor in this 
study because a lack of variation in the student sex composition of the institutions in our sample makes it difficult to examine in multivariate analyses.

4. We attempted a complete census of western departments to obtain longitudinal data for a five-year follow-up to a prior survey of departments in the Pacific Sociological Association region (Nigg and Axelrod 1981). This produces an unusual situation with respect to statistical inference, because our parameter estimates for the western region have virtually no sampling error. We still report statistical significance information as if all the departments were part of a typical random sample, but note results that meet a somewhat relaxed $(p<.10)$ threshold of statistical significance.

5. For each department, the index of dissimilarity would be defined as:

$$
D=\frac{1}{2} \sum_{i=1}^{N}\left(X_{i}-Y_{i}\right)
$$

where $x_{i}=$ the percent female in the $i^{\text {th }}$ category of academic rank, and $y_{i}=$ the percent male in that same category. This generates the proportion of women who would have to switch academic ranks in order to eliminate differences in rank between men and women within a department. The index we use-H-makes an adjustment in $\mathbf{D}$ based on the degree of skewness in the overall sex composition of the faculty. The two measures $-\mathbf{H}$ and D-are highly correlated $(r=.85)$, and results were comparable, though not identical, using either index in regression analyses. Here we report results only for $\mathbf{H}$. 6. Sociology departments offering only bachelor degrees and those granting master degrees but not the Ph.D. were compared with those granting doctoral degrees. Carnegie classifications were used to distinguish "Research Universities" I and II from "Comprehensive Universities" and "Liberal Arts" colleges.
7. For the minority of schools that reported only ACT scores for entering freshmen, we standardized the average ACT score and converted it to an estimated SAT score (Lindquist 1964). The factor analysis did not incorporate any of the available reputational measures of the prestige of the sociology department. We chose institution-wide measures of the quality of the undergraduate program because empirically-based ratings for sociology are limited to departments with graduate programs (Jensen and Webster 1981) and are strongly related to the department's research orientation (Jones, Lindzey and Coggeshall 1982), which was measured separately in the analysis.

8. We identified four-year institutions from the HEGIS/IPEDS Institutional Characteristics Survey, and used the U.S. Bureau of the Census 1987 City Reference File to convert zip codes to MSAs.

9. The study by Blair and Savage (1984) of these state policies identifies nine separate, and largely independent, factors. It reports no global pattern of receptivity to issues of equity for women, but a multidimensional arena of action and inaction in different areas. Most states have mixtures of policies that seem less than consistent. The study also shows that regional variations account for the distribution of some of the policies taken singly, but not for the underlying patterns revealed in the factor analysis.

10. The index does not generate extreme values for departments with faculty all of the same sex; it assigns an intermediate value (.5) that is halfway between its upper and lower bounds. Rather than arbitrarily reassigning the values given to these same-sex departments, which comprise about twenty percent of the sample, we have excluded them from the analysis. 11. Since department chairs serve on many committees simply by virtue of their office, they are excluded from the committee analysis. 
12. The sex of the department chair was omitted from this table. It is by far the most powerful predictor, but its causal role here is especially questionable. The selection of a female department chair would seem to require a female at advanced academic rank, while the odds of her election would be enhanced through numbers alone in departments with more balanced sex ratios. The inclusion of this variable does not alter the pattern of significant effects among the remaining variables.

\section{REFERENCES}

Abramson, Joan. 1975. The Invisible Woman: Discrimination in the Academic Profession. San Francisco: Jossey-Bass.

Aisenberg, Nadya and Mona Harrington. 1988. Women of Academe: Outsiders in the Sacred Grove. Amherst: University of Massachusetts Press.

Astin, Helen S. and Alan E. Bayer. 1979. "Pervasive Sex Differences in the Academic Reward System: Scholarship, Marriage, and What Else?" Pp. 211-229 in Academic Rewards, edited by Darrell R. Lewis and William E. Becker, Jr. Cambridge, MA: Ballinger.

Bach, Rebecca L. and Carolyn C. Perrucci. 1984. "Organizational Influences on the Sex Composition of College and University Faculty: A Research Note." Sociology of Education 57:193-198.

Baron, James N. and William T. Bielby. 1980. "Bringing the Firms Back In: Stratification, Segmentation and the Organization of Work." American Sociological Review 45: 737-765.

1982. "Workers and Machines: Dimensions and Determinants of Technical Relations in the Workplace." American Sociological Review 47:175-188.

Bernard, Jessie. 1964. Academic Women. University Park: Pennsylvania State University Press.
1975. "Research on Sex Differences: An Overview of the Art." Pp. 7 29 in Women, Wives and Mothers: Values and Options. Chicago: Aldine.

Bielby, William T. and James N. Baron. 1984. "A Woman's Place Is with Other Women: Sex Segregation within Organizations." Pp. 27-55 in Sex Segregation in the Workplace: Trends, Explanations, Remedies, edited by Barbara F. Reskin. Washington, DC: National Academy Press.

Blair, Diane D. and Robert L. Savage. 1984. "Dimensions of Responsiveness to Women's Policies in the Fifty States." Women and Politics 4:49-68.

Blau, Peter M. 1973. The Organization of Academic Work. New York: Wiley.

Caplow, Theodore and R. McGee. 1958. The Academic Marketplace. New York: Basic Books.

Carnegie Foundation for the Advancement of Teaching. 1987. A Classification of Higher Educational Institutions. Princeton, NJ: Carnegie Foundation for the Advancement of Teaching.

Carter, Susan B. 1981. "Academic Women Revisited: An Empirical Study of Changing Patterns in Women's Employment as College and University Faculty, 1890-1963." Journal of Social History 14:675-699.

Carter, Michael J. and Susan B. Carter. 1981. "Women's Recent Progress in the Professions, or, Women Get a Ticket to Ride after the Gravy Train Has Left the Station." Feminist Studies 7:477-504.

Child, John. 1972. "Organizational Structure, Environment and Performance: The Role of Strategic Choice." Sociology 6:1-22.

1973. "Predicting and Understanding Organizational Structure." $A d-$ ministrative Science Quarterly 18:168-185.

Cole, Jonathan R. 1979. Fair Science: Women in the Scientific Community. New York: Free Press.

Cole, Jonathan and Harriet Zuckerman. 
1987. "Marriage, Motherhood and Research Performance in Science." Scientific American 255:119-125.

Coyle, Susan. 1986. Summary Report 1985: Doctorate Recipients from United States Universities. Washington, DC: National Academy Press.

Crane, Diana. 1972. Invisible Colleges. Chicago: University of Chicago Press.

Cyert, Richard M. and James G. March. 1963. A Behavioral Theory of the Firm. Englewood Cliffs, NJ: Prentice-Hall.

DiNitto, Diana, Patricia Yancy Martin, and Dianne F. Harrison. 1982. "Sexual Discrimination in Higher Education." Higher Education Review 14:33-54.

Duncan, Otis D. and Beverly Duncan. 1955. "A Methodological Analysis of Segregation Indexes." American Sociological Review 20:210-217.

England, Paula. 1982. "The Failure of Human Capital Theory to Explain Segregation." Journal of Human Resources 17:371392.

Ferber, Marianne. 1988. "Citations and Networking." Gender and Society 2:8289.

Fox, Mary Frank. 1983. "Publication Productivity among Scientists: A Critical Review." Social Studies of Science 13:285305.

Graham, Patricia A. 1978. "Expansion and Exclusion: A History of Women in Higher Education." Signs 3:759-773.

Jensen, Eric L. and David Webster. 1981. "Ranking Studies of Sociology Departments in The American Sociologist: 1965-1980." Paper presented at the annual meeting of the American Educational Research Association, Los Angeles.

Jones, Katharine and Patricia A. Roos. 1991. "The Feminization of Sociology?" Paper presented at the annual meeting of the American Sociological Association, Cincinnati, $\mathrm{OH}$.

Jones, Lyle V., Gardner Lindzey, and Porter Coggeshall, eds. 1982. An Assessment of Research-Doctorate Programs in the United States. Washington, DC: National Academy Press.

Kalleberg, A.L. and A.B. Sörensen. 1979. "The Sociology of Labor Markets." Annual Review of Sociology 5:351-379.

Kanter, Rosabeth Moss. 1977. Men and Women of the Corporation. New York: Basic Books.

Kenen, Peter B. and Regina H. Kenen. 1978. "Who Thinks Who's in Charge Here: Faculty Perceptions of Influence and Power in the University." Sociology of Education 51:113-123.

Kimberly, J.R. 1976. “Organizational Size and the Structuralist Perspective: A Review, Critique and Proposal." Administrative Science Quarterly 21:571-597.

Knorr-Centina, Karin D. 1981. The Manufacture of Knowledge: An Essay on the Constructivist and Contextual Nature of Science. New York: Pergamon Press.

Kulis, Stephen. 1988. "The Representation of Women in Top Ranked Sociology Departments." The American Sociologist 19:203-217.

Kulis, Stephen, and Karen A. MillerLoessi. 1992. "Organizational Dynamics and Gender Equity: The Case of Sociology Departments in the Pacific Region." Work and Occupations 19:157-183.

Kulis, Stephen, Karen A. Miller, Morris Axelrod, and Leonard Gordon. 1986. "Minorities and Women in the PSA Region: Five Years Later." Sociological Perspectives 29:147-176.

Leatherman, Courtney. 1991. "Colleges Hire More Female Presidents, but Questions Linger about Their Clout." Chronicle of Higher Education 37[6] November:A19-21.

Lindquist, E.F. 1964. “Equating Scores on Non-Parallel Tests." Paper presented at the annual meeting of the American Educational Research Association, Chicago. Reprint available from the American College Testing Service, Iowa City, Iowa. 
Lyle, Jerolyn R. and Jane L. Ross. 1973. Women in Industry: Employment Patterns of Women in Corporate America. Lexington, MA: Lexington Books.

Mackie, Marlene. 1985. "Female Sociologists' Productivity, Collegial Relations, and Research Style Examined through Journal Publications." Sociology and Social Research 69:189-209.

Marwell, Gerald, Rachel A. Rosenfeld, and Seymour Spilerman. 1979. "Geographic Constraints on Women's Careers in Academia." Science 205:12251231.

Max, Claire. 1982. "Career Paths for Women in Physics." Pp. 99-116 in Women and Minorities in Science: Strategies for Increasing Participation, edited by Sheila M. Humphreys. Boulder, CO: Westview.

Mayhew, Leon H. 1968. Law and Equal Opportunity: A Study of the Massachusetts Commission Against Discrimination. Cambridge: Harvard University Press.

McGinnis, Robert and J. Scott Long. 1988. "Entry into Academia: Effects of Stratification, Geography and Ecology." Pp. 28-51 in Academic Labor Markets and Careers, edited by David W. Breneman and Ted I. K. Youn. New York: Falmer Press.

National Research Council. 1979. Survey of Earned Doctorates Awarded in the United States: Social and Behavioral Sciences. Washington, DC: National Academy Press.

National Science Foundation. 1990. Characteristics of Recent Science and Engineering Graduates: 1988. NSF 90-305. Washington, DC.

Nigg, Joanne and Morris Axelrod. 1981. "Women and Minorities in the PSA Region: Results of the 1979 Survey." Pacific Sociological Review 24:107-128.

Perrucci, Carolyn C. 1986. "Gender Equity in Sociology Faculty Employment Patterns: A Cross-university Comparison." Sociology and Social Research 70:235-241.
Pfeffer, Jeffrey. 1977. "Toward an Examination of Stratification in Organizations." Administrative Science Quarterly 22:553-567.

Pfeffer, Jeffrey and Gerald R. Salancik. 1978. The External Control of Organizations. New York: Harper and Row.

Reskin, Barbara F. 1980. "Fair Science: A Fair Test?" A Review of Jonathan Cole's Fair Science. Contemporary Sociology 9:793-795.

Reskin, Barbara F. and Patricia A. Roos. 1990. Job Queues, Gender Queues. Philadelphia: Temple University Press.

Rong, Xue Lan, Linda Grant, and Kathryn B. Ward. 1988. "Funding and Sociological Publication: Effects of Method, Gender and Topic." Paper presented at the annual meeting of the American Sociological Association, Atlanta.

Roos, Patricia A. and Barbara F. Reskin. 1992. "Occupational Desegregation in the 1970s: Integration and Economic Equity?" Sociological Perspectives 35:69-91.

Rosenfeld, Rachel A. 1984. "Academic Career Mobility for Women and Men Psychologists." Pp. 89-127 in Women in Scientific and Engineering Professions, edited by V. B. Haas and C. C. Perrucci. Ann Arbor: University of Michigan Press.

Salancik, Gerald R. 1979. "Interorganizational Dependence and Responsiveness to Affirmative Action: The Case of Women and Defense Contractors." Academy of Management Journal 22:375394.

Schwartz, Eleanor Brantley. 1971. The Sex Barrier in Business. Atlanta: Bureau of Business and Economic Research, Georgia State University.

Shepherd, William G. 1969. "Market Power and Racial Discrimination in White Collar Employment." The AntiTrust Bulletin 14:141-161.

Shepherd, William and Sharon G. Levin. 1973. "Managerial Discrimination in 
Large Firms." Review of Economics and Statistics 55:412-422.

Simeone, Angela. 1987. Academic Women: Working Towards Equality. South Hadley, MA: Bergin and Garvey.

Smelser, Neil and Robin Content. 1980. The Changing Academic Market. Berkeley: University of California Press.

Szafran, Robert F. 1982. "What Kinds of Firms Hire and Promote Women and Blacks? A Review of the Literature." Sociological Quarterly 23:171-190.

- 1984. Universities and Women Faculty: Why Some Organizations Discriminate More than Others. New York: Praeger.

Theil, Henri and Anthony J. Finizza. 1971.
"A Note on the Measurement of Racial Integration of Schools by Means of Informational Concepts." Journal of Mathematical Sociology 1:187-194.

Thibault, Gisele. 1987. The Dissenting Feminist Academy. New York: P. Lang.

Tolbert, Pamela S. 1986. "Organizations and Inequality: Sources of Earnings Differentials between Male and Female Faculty." Sociology of Education 59:227235.

Vetter, Betty M. 1984. "Patterns of Recruitment and Employment." Pp. 59-74 in Women in Scientific and Engineering Professions, edited by V. B. Haas and C. C. Perrucci. Ann Arbor: University of Michigan Press. 